\title{
Mapping Physicians' Experiences with Medicinal Products from Whole Medical Systems: A Descriptive Analysis of the Vademecum of Anthroposophic Medicines
}

\author{
Harald Johan Hamre ${ }^{a, b}$ Anja Glockmann ${ }^{a, b}$ Jakob Martic,d Georg Soldner ${ }^{b, c}$ \\ anstitute for Applied Epistemology and Medical Methodology at the Witten/Herdecke University, Freiburg,

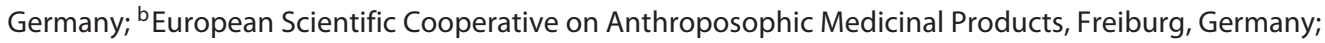 \\ 'Association of Anthroposophic Physicians in Germany, Munich, Germany; ${ }^{\mathrm{d}}$ Interleave GmbH, Munich, Germany
}

\section{Keywords}

Anthroposophic Medicine $\cdot$ Clinical experience .

Cross-sectional studies · Medicinal products .

Practice-based evidence $\cdot$ Whole medical systems

\begin{abstract}
Background: Therapy in whole medical systems involves a large number of medicinal products. One source of knowledge of clinical properties of such products is the experience of therapy providers. A systematic approach to documentation, assessment, and aggregation of physicians' experiences with anthroposophic medicinal products (AMPs) has been developed: the Vademecum of Anthroposophic Medicines. Material and Methods: The Vademecum contains structured information on AMPs, including therapeutic rationale, indications, and therapy recommendations. The information is based on a 17-item questionnaire of physicians' therapy experiences, which is peer-reviewed by an interdisciplinary editorial board. We conducted a descriptive analysis of the $\mathrm{Va}$ demecum, 4th edition. Results: The Vademecum comprised 799 different AMPs, used for 1,773 indications, based on 2,543 questionnaires submitted by 274 physicians from 19 countries. The 799 AMPs comprised $52.6 \%$ of all AMPs marketed in Germany in 2015-2016. The 1,773 indications corresponded to 544 different ICD-10 three-digit codes,
\end{abstract}

\section{karger@karger.com} www.karger.com/cmr

Karger $\frac{1}{\%}$ BOPEN ACCESS
(C) 2020 The Author(s)

Published by S. Karger AG, Basel

This article is licensed under the Creative Commons Attribution NonCommercial-NoDerivatives 4.0 International License (CC BYNC-ND) (http://www.karger.com/Services/OpenAccessLicense). Usage and distribution for commercial purposes as well as any distribution of modified material requires written permission. amounting to $29.3 \%(n=544 / 1,854)$ of all three-digit codes. A total of $30.6 \%(n=542 / 1,773)$ of indications were supported by $\geq 2$ questionnaires. Conclusions: The current Vademecum covers more than half of all AMPs, used for more than one fourth of all ICD-10 three-digit codes. The Vademecum approach may be relevant for medicinal products from other whole medical systems.

(c) 2020 The Author(s)

Published by S. Karger AG, Basel

Systematik ärztlicher Anwendungserfahrungen mit Arzneimitteln aus ganzheitlichen Therapiesystemen: Eine deskriptive Analyse des Vademecum anthroposophischer Arzneimittel

\section{Schlüsselwörter}

Anthroposophische Medizin · Klinische Erfahrung • Spezialitätenübergreifende Studien · Arzneimittel · Praxisbasierte Evidenz · Ganzheitliche Therapiesysteme

\section{Zusammenfassung}

Hintergrund: Zur Behandlung in ganzheitlichen Therapiesystemen stehen eine große Anzahl von Arzneimitteln zur Verfügung. Eine Informationsquelle über die klinische 
Anwendung solcher Arzneimittel sind die Erfahrungen der Ärzte bzw. Therapeuten. Für Arzneimittel der anthroposophischen Medizin (AM) wurde ein System zur Dokumentation, Bewertung und Zusammenstellung ärztlicher Anwendungserfahrungen entwickelt: das Vademecum anthroposophische Arzneimittel. Material und Methodik: Das Vademecum enthält strukturierte Angaben zu AMArzneimitteln, einschließlich therapeutischer Ratio, Indikationen und Anwendungsempfehlungen. Die Angaben basieren auf der Dokumentation ärztlicher Anwendungserfahrungen mittels 17-Punkte-Bögen, die anschließend von einer interdisziplinären Redaktionsgruppe überprüft werden. Wir stellen hier eine deskriptive Analyse des $\mathrm{Va}$ demecum, 4. Auflage, vor. Ergebnisse: Das Vademecum umfasst 799 unterschiedliche AM-Arzneimittel, die für 1'773 Indikationen empfohlen werden, basierend auf 2'543 Dokumentationsbögen, die von 274 Ärzten aus 19 Ländern ausgefüllt worden waren. Die 799 AM-Arzneimittel machen 52,6\% aller AM-Arzneimittel aus, die in den Jahren 2015-2016 in Deutschland auf dem Markt waren. Die 1'773 Indikationen entsprechen 544 unterschiedlichen dreistelligen ICD-10-Codes, was 29,3\% ( $n=544$ / 1 '854) aller dreistelligen ICD-10-Codes ausmacht. Insgesamt 30,6\% ( $\left.n=542 / 1^{\prime} 773\right)$ aller Indikationen basieren auf 2 oder mehr Dokumentationsbögen. Schlussfolgerung: Das heutige Vademecum deckt mehr als die Hälfte aller AM-Arzneimittel und mehr als ein Viertel aller dreistelligen ICD-10-Codes ab. Der Vademecum-Ansatz kann auch für Arzneimittel aus anderen ganzheitlichen Therapiesystemen relevant sein.

(c) 2020 The Author(s) Published by S. Karger AG, Basel

\section{Introduction}

\section{Whole Medical Systems with Medicinal Products}

Whole medical systems are complete systems of theory and practice that have evolved in different regions, cultures and time periods, mostly apart from Western, conventional medicine $[1,2]$. Whole medical systems include anthroposophic medicine, ayurveda, naturopathy, traditional Chinese medicine, and unani medicine [2].

Features of whole medical systems include a tradition of use prior to the emergence of current conventional medicine, a holistic, non-reductionist ontological, epistemological and practice orientation, specific diagnostic and therapeutic typologies, and the use of a large number of medicinal products (WMPs, medicinal products from whole medical systems) of herbal, zoological or mineral origin. Because of the different typologies in whole medical systems and conventional medicine, WMPs are often used for a number of different indications according to conventional disease classification [2].

\section{Experiential Literature on Medicinal Products from}

Whole Medical Systems

Historically, the experiences with WMPs have been summarized in texts (often titled "handbook," "materia medica," "pharmacopoeia," "vademecum," or similar) describing indications, contraindications, therapy recommendations, etc. From the second part of the 20 th century onwards, clinical studies have been performed for a number of WMPs. Nonetheless, because of the large number of WMPs and indications, it is not feasible to conduct clinical studies for each indication for each WMP [2]. Therefore, for a large proportion of WMPs, the requirements for obtaining regular marketing authorization (including effect documentation in controlled clinical trials) cannot be met. However, a number of countries have established separate regulatory provisions for some types of WMPs, making use of other types of evidence, including experiential reports, in order to demonstrate at least some plausibility for effects (e.g., Canada [3], Switzerland [4], the European Union [5]).

Much of the experiential literature on WMPs has limitations: therapy recommendations based on the experience of one or a few therapy providers; limited data on how the experiences came about (e.g., what kind of setting, how many patients were treated over what time period); lack of information on how the experiences were aggregated and assessed (e.g., review of medical case records or global recollection from memory).

It should be possible to improve the quality of the experiential literature by a more systematic approach, e.g. incorporating experiences from several therapy providers from different settings and regions, using detailed systematic description of the experiences as well as transparent procedures for data collection and more explicit criteria for the assessment. In this paper we present a quantitative descriptive analysis of one such systematic approach to the therapy experiences with medicinal products from AM.

\section{$A M$ and Anthroposophic Medicinal Products}

AM is an integrative whole medical system, founded in Central Europe in the early 1920s by Rudolf Steiner and Ita Wegman [6]. In contrast to most whole medical systems, AM was developed within conventional, Western medicine and is provided by estimated 19,000 physicians in inpatient hospitals and outpatient settings around the world [7]. Physicians are trained in AM according to an international, standardized curriculum but they also use contemporary disease classification systems alongside with AM diagnostic typologies. Medicinal products from AM (AMPs) are manufactured according to specific AM procedures or homoeopathic procedures (involving successive 1:10 dilutions labelled D1, D2, etc.) according to Good Manufacturing Practice and national drug regula- 
Table 1. Classification of anthroposophic medicinal product (AMP) groups and individual AMPs

\begin{tabular}{ll}
\hline Level & Description \\
\hline 7 & $\begin{array}{l}\text { AMPs with identical type of starting material or } \\
\text { manufacturing procedures }\end{array}$ \\
6 & $\begin{array}{l}\text { AMPs with similar starting materials and } \\
\text { manufacturing procedures }\end{array}$ \\
5 & $\begin{array}{l}\text { AMPs with identical starting material but different } \\
\text { manufacturing procedures }\end{array}$ \\
4 & $\begin{array}{l}\text { AMPs with identical manufacturer and starting } \\
\text { material, but with different dosage forms }\end{array}$ \\
3 & $\begin{array}{l}\text { AMP, including different concentration and pack sizes } \\
\text { Specific concentration of an AMP }\end{array}$ \\
1 & Specific concentration and pack size of an AMP \\
\hline
\end{tabular}

tions [8]. The available evidence suggests that AMPs are generally well tolerated, with infrequent adverse reactions of mostly mild to moderate severity $[9,10]$.

AMP therapy is used in virtually all medical fields [6] and involves well over 1,000 products, often used in different combinations [11-15]. Accordingly, for AMP therapy there are several thousand therapy options. Clinical studies have mainly been conducted for mistletoe AMPs and approximately 50 other AMPs [9].

\section{Vademecum of Anthroposophic Medicines}

The Vademecum of Anthroposophic Medicines [15] (from Latin: vade mecum - "walk with me," henceforth abbreviated Vademecum) is essentially a collection of structured information about a large number of AMPs, including therapeutic rationale, indications, recommendations for use, and literature references. The Vademecum is based on a structured documentation of therapy experiences of several hundred physicians, which is peerreviewed and processed by an interdisciplinary editorial board (qualifications and demographics of participating physicians and board members are presented in the Results section). The project is independent of AMP manufacturers.

The Vademecum originated in an international survey among AM physicians in 2006-2007 and was first published in German in 2008. Since then revised editions and translations (English, Spanish, French, Italian) have appeared; the current 4th German edition was published in 2017 [15]. (In addition, there exists an online Vademecum External Applications in Anthroposophic Nursing, $\mathrm{http}: / / w w w . p f l e g e-v a d e m e c u m . d e$, which is not dealt with in this paper.)

The primary target group for the Vademecum are physicians prescribing AMPs. The Vademecum is published in printed and electronic editions, with information structured according to AMP groups. These groups are pragmatically defined by the Vademecum editorial board, whereby each AMP group may include one or several different AMPs with identical or similar starting materials, manufacturing processes or dosage forms, corresponding to the levels 2-6 in Table 1 . The information text on each AMP group includes the following items (some items are not provided for all AMPs or indications):

- For each AMP group: name with synonyms, composition, dosage forms, manufacturers, therapeutic rationale according to AM, regulatory approved indications in Germany, literature references

- For each indication of each AMP group: name of indication, typical symptoms, dosage recommendation, onset of action, therapy duration, adjunctive or differential therapy, contraindications, adverse reactions, strength of recommendation, name of the reporting physicians

The information in the Vademecum is compiled by a collaboration between the editorial board and reporting physicians: all AM physicians from any country are eligible for participation. For the preparation of new editions, reporting physicians are asked to submit two types of questionnaires, each referring to one indication for one AMP group:

For AMP groups and indications that have not been published in previous Vademecum editions, physicians document their therapy experiences in a "new report questionnaire" consisting of 17 items, covering the following topics:

- AMP group: name, manufacturers, country of manufacture

- Description of indication, typical symptoms and findings, triggers and causes, age and gender, constitution type, other relevant modalities

- Dosage: general, for adults and for children

- Time until the effect can be expected or time after which ineffectiveness must be assumed if no effect is registered, first symptoms to improve, average treatment duration

- Adverse reactions, adjunctive and differential therapies

- Approximate number of cases successfully treated in this way, how certain is the physician about the effectiveness of this product

- Additional literature

Each submitted new report is peer reviewed by the editorial board, resulting in either acceptance of the report, request to the reporting physician for clarification, completion of the questionnaire responses, or rejection of the report.

The contents of the accepted new reports are enhanced by therapy experiences of the editorial board members and, if necessary, by a narrative literature review. If the editorial board concludes that the experiential evidence is sufficient for inclusion of the new AMP group and/or 
new indication into the next Vademecum edition, an information text is written in a consensual process among board members. If the evidence is deemed insufficient, the data are stored in the project database and may be used for subsequent revisions.

For each indication, the strength of recommendation is classified by the editorial board in a consensus process into one of three categories [16]:

- "Well-established, standard AMP therapy" ("both with respect to breadth of application and evidence of effectiveness")

- "Normal indications" ("sufficiently broadly anchored in the observations of experienced, qualified colleagues and therefore suitable for publication")

- "Indications requiring further experience and review" ("because current published medical knowledge is not yet adequate")

For indications that have been previously published, physicians are encouraged to submit "feedback questionnaires" with confirmation of perceived effectiveness of the AMP for the indications in question, reports of noneffectiveness or additional information. This feedback is assessed by the editorial board and, if accepted, incorporated into subsequent Vademecum editions, including the name of the reporting physician.

In the 4th German edition [15], the information on the AMP group of mistletoe (Viscum album) products, which are used for cancer and other indications [17], has been expanded into a section of 303 pages, including additional subsections on botany, manufacturing procedures, protocols for specific indications, and overview of clinical trials.

\section{Context for and Aim of the Present Analysis}

There is a need for an adequate framework for registration and marketing authorization of AMPs in Europe and worldwide. With regard to this need, the European Scientific Cooperative on Anthroposophic Medicinal Products (ESCAMP - http://www.escamp.org/) was founded. One of the tasks of ESCAMP is to compile and publish research syntheses of the available scientific documentation on the pharmaceutical quality, safety, and efficacy/effectiveness of the entire group of AMPs.

The aim of this analysis is to provide a quantitative description of the Vademecum, including the number of AMPs and indications (absolute and relative to all AMPs on the market and all indications for AMP treatment, respectively) and the amount of experiential evidence per indication.

\section{Materials and Methods}

Object of the Analysis

The object of this descriptive quantitative analysis was the $\mathrm{Va}$ demecum, 4th German edition [15] (henceforth "Vademecum").

\section{Main Research Questions}

- Quantitative description of participating physicians, new report questionnaires, AMPs and their pharmaceutical properties, indications for AMP therapy, safety

- Relative frequencies of AMPs in the Vademecum versus AMPs on the market, indications in the Vademecum versus all indications in medicine

\section{Variables Analysed}

- Participating physicians: gender, country, number of years since medical licensing, specialist qualification, and (only available for editorial board members) setting

- New report questionnaires: country of reporting physician

- Feedback questionnaires: impact on editorial assessment (confirmation of perceived effectiveness of the AMP for the indication in question, addition of critical comments)

- Pharmaceutical properties of AMPs: starting materials, concentration of active substances, route of administration

- Regulatory status of AMPs marketed in Germany: marketing authorization or registration with or without indication

- Indications: classification, strength of recommendation according to the assessment of the Vademecum editorial board ("well-established, standard AMP therapy"/"normal indications"/ "indications requiring further experience and review")

- Therapy experiences and recommendations: therapeutic action, onset of action (time until the effect can be expected), therapy duration, adjunctive therapy, adverse reactions, contraindications

- Literature references: type and language of reference

\section{Definitions and Classification}

The term "AMP groups" in this paper corresponds to the terms "Medicines" and "Arzneimittel" in the English and German $\mathrm{Va}$ demecum editions, respectively.

AMPs were defined according to the German Medicines Act [18]. For practical purposes, all medicinal products marketed in Germany by the manufacturers Abnoba (Pforzheim, Germany), Helixor (Rosenfeld, Germany), Wala (Bad Boll, Germany), and Weleda (Arlesheim, Switzerland) were classified as AMPs.

AMPs on the German market in the period 2015-2016 were defined as AMPs listed at least once in the pharmaceutical catalogues published by the AMP manufacturers in the years 2015 and 2016.

For AMPs, the main unit of analysis was each product with a separate registration or marketing authorization, corresponding to AMPs with a separate entry in the pharmaceutical catalogues of the respective manufacturers. This category includes different potencies and pack sizes of otherwise identical AMPs (level 3 in Table 1). Accordingly, AMPs listed together within a separate entry but marketed in different concentrations or pack sizes were grouped together.

For individual AMPs and AMP groups, generic terms were used; for AMPs with more than one starting material, all starting materials were listed.

The term "indication" in this paper refers to indications described in the Vademecum and does not imply that the respective product is approved for the "indication" in Germany or any other country.

\section{Data Collection and Preparation}

Two variables pertaining to the participating physicians (number of years since medical licensing, specialist qualification) were not documented in the Vademecum project. As a substitute, corresponding data were extracted from the database of the Association of Anthroposophic Physicians in Germany (GAÄD). From 
this database, number of years since medical licensing was available for $43.8 \%(n=116 / 265)$ of all physicians and for $66.3 \%(n=$ $110 / 166)$ of physicians from Germany. Specialist qualification was available for $74.3 \%(n=197 / 265)$ of all physicians and for $78.3 \%$ ( $n=130 / 166)$ of physicians from Germany. Missing data were not replaced.

All other data were extracted from the Vademecum database (Interleave $\mathrm{GmbH}$, Munich, Germany), using SQL queries. The Vademecum database contains all texts and data in the Vademecum since the first edition from 2008; for the variables analysed in this paper, there were no missing data.

The AMP groups of the Vademecum were coded as level 3 AMPs (Table 1) by checking with the ESCAMP database of AMPs (ESCAMP e.V., Freiburg, Germany). The ESCAMP database contains, amongst others, detailed pharmaceutical data for all AMPs marketed in Germany since 2000.

Pharmaceutical properties of AMPs were classified according to the Anthroposophic Pharmaceutical Codex (APC 4.1 [8]). For analysis of starting materials of mineral origin, the categories 2.1 and 2.4 in the APC were grouped together.

Indications were coded according to the International Classification of Diseases, 10th revision (ICD-10). Adverse reactions were coded according to the Medical Dictionary for Regulatory Activities (MedDRA, version 19.0, MedDRA MSSO, McLean, VA, USA).

The variables "onset of action" and "therapy duration" were documented in free text and categorized for analysis. For both variables, a proportion of responses was given as ranges (e.g., 1-3 days). For the analyses the maximum time period was used.

For calculation of the concentration or decimal potency of AMPs with more than one active substance, the substance with the lowest potency was used. For AMPs of the group Iscucin, which are potentized in successive 1:20 dilution, the corresponding decimal potency (1:10 dilution) was used.

\section{Data Analysis}

Data analysis was performed using IBM SPSS Statistics $25^{\circledR}$ (International Business Machines Corp., Armonk, NY, USA). Analysis was descriptive without hypothesis testing. The relative frequencies of AMPs in the Vademecum versus AMPs on the German market were analysed in subgroups according to marketing status in Germany (all 2 subgroups), route of administration (3 most frequent subgroups) and origin of starting material (3 most frequent subgroups).

\section{Results}

\section{Overview}

The Vademecum comprised 625 different AMP groups used for 1,773 different indications, based on a total of 2,543 new report questionnaires submitted by 274 physicians. The 1,773 indications were supplemented with a total of 19,328 citations of 2,389 different literature references.

\section{Participating Physicians and New Report \\ Questionnaires}

Of the 274 participating physicians, 264 submitted questionnaires individually, while 10 physicians from Milan, Italy, submitted questionnaires collectively. In the present analysis, the latter 10 physicians were counted as one, resulting in $n=265$ physicians. These were working in Germany $(62.6 \%, n=166 / 265)$, Switzerland $(13.6 \%$, $n=36)$, the Netherlands $(6.0 \%, n=16)$, Austria $(3.8 \%$, $n=10)$, Italy $(3.8 \%, n=10)$, France $(2.3 \%, n=6)$, Sweden $(1.9 \%, n=5)$, or other countries $(6.0 \%, n=16)$, altogether in 19 different countries. A total of $65.3 \%(n=173 / 264)$ of physicians were men and $34.3 \%(n=91)$ were women. Physicians had a mean 33.5 years (standard deviation [SD] 9.9, median 33.0 years, interquartile range [IQR] $26-40$ years, range $10-66$ years, $n=116$ physicians evaluable for this item) of experience since their medical licensing and were qualified as family physicians $(54.8 \%$, $n=108$ of 197 evaluable physicians), internists (15.7\%, $n=31)$, paediatricians $(10.2 \%, n=20)$, gynaecologists $(5.6 \%, n=11)$, neurologists $(2.5 \%, n=5)$, or another of 8 different specialties $(11.2 \%, n=22)$.

The editorial board preparing the 4 th edition of the Vademecum consisted of 10 physicians ( 8 male, 2 female, all 10 were also participating physicians) from 4 countries (Austria, Brazil, Switzerland, Germany) with specialist qualification in family medicine $(n=2)$, paediatrics $(n=$ $2)$, obstetrics and gynaecology $(n=1)$, internal medicine $(n=6)$, haematology and oncology [2]. Their medical work was or had been mainly in inpatient hospitals $(n=$ 4) and outpatient settings $(n=6)$.

The 2,543 new report questionnaires were submitted from: Germany ( $63.7 \%$ of reports, $n=1,619 / 2,543)$, Switzerland $(12.8 \%, n=325)$, Italy $(9.7 \%, n=246)$, Austria $(6.5 \%, n=166)$, the Netherlands $(2.0 \%, n=51)$, or from other countries $(5.3 \%, n=136)$.

Each physician submitted 1-4 new report questionnaires (66.4\% of physicians, $n=176 / 265)$, 5-9 questionnaires $(17.0 \%, n=45), 10-19$ questionnaires $(8.3 \%, n=$ $22)$ or $\geq 20$ questionnaires $(8.3 \%, n=22)$ with a median of 3 questionnaires per physician (IQR 1-7, mean 9.6, range 1-231 questionnaires).

\section{AMP Groups and AMPs}

Of the 625 AMP groups, $23.0 \%(n=144)$ had a description of the therapeutic action.

A total of $97.3 \%$ ( $n=608 / 625)$ of AMP groups were marketed in at least one country, $1.6 \%(n=10)$ were available as magistral prescription, and $1.1 \%(n=7)$ were not AMPs according to the definition (see Methods section) (other medicinal products: $n=3$, body care products: $n=4)$.

Of the 608 AMP groups marketed in at least one country, $n=586$ (96.4\%) were marketed in Germany, corresponding to 799 different AMPs (level 3 in Table 1). All following results in this section refer to these 799 AMPs.

Of the 799 AMPs, $63.2 \%(n=505 / 799)$ had a marketing authorization or registration with indication while $36.8 \%(n=294)$ were marketed without indication. With a few exceptions, these two categories correspond to 
Table 2. Concentration of anthroposophic medicinal products (AMPs) ${ }^{1}$

\begin{tabular}{lrc}
\hline Concentration & Number & Percent \\
\hline Concentrated form ${ }^{2}$ & 180 & 10.7 \\
Mother tincture & 56 & 3.3 \\
D1 & 39 & 2.3 \\
D2 & 117 & 7.0 \\
D3 & 168 & 10.0 \\
D4 & 87 & 5.2 \\
D5 & 124 & 7.4 \\
D6 & 235 & 14.0 \\
D7-D11 & 232 & 13.8 \\
D12-D15 & 210 & 12.5 \\
D16-D30 & 229 & 13.6 \\
D40-D60 & 6 & 0.4 \\
\hline Total AMPs & 1,683 & 100.0 \\
\hline
\end{tabular}

${ }^{1}$ AMPs of level 2 in Table 1. For AMPs with more than one active substance, the highest concentration or lowest potency is used. ${ }^{2}$ Neither potentized nor mother tincture.

Table 4. Anthroposophic medicinal product (AMP) groups with at least 10 indications each

\begin{tabular}{llrc}
\hline \multirow{2}{*}{ AMP group } & \multicolumn{2}{c}{ Indications } \\
\cline { 3 - 4 } & $n$ & \multicolumn{2}{c}{$\%$} \\
\hline 1 & Viscum album & 85 & 4.8 \\
2 & Argentum metallicum praeparatum & 17 & 1.0 \\
3 & Onopordum/Hyoscyamus/Primula & 14 & 0.8 \\
4 & Aurum metallicum praeparatum & 13 & 0.7 \\
5 & Formica & 12 & 0.7 \\
6 & Arandisite & 11 & 0.6 \\
7 & Belladonna & 11 & 0.6 \\
8 & Mercurius vivus naturalis & 11 & 0.6 \\
9 & Quartz & 11 & 0.6 \\
10 & Aesculus/Equisetum/Solum & 11 & 0.6 \\
11 & Stibium metallicum praeparatum & 11 & 0.6 \\
12 & Arnica (planta tota) & 10 & 0.6 \\
13 & Ferrum sulfuricum/Mel/Vinum/Quartz & 10 & 0.6 \\
14 & Phosphorus & 10 & 0.6 \\
15 & Plantago/Primula/Hyoscyamus & 10 & 0.6 \\
& All other AMP groups & 1,526 & 86.1 \\
\hline & Total indications & 1,773 & 100.0 \\
\hline
\end{tabular}

AMPs manufactured according to an anthroposophic or homoeopathic procedure, respectively.

Starting material for the AMPs was a single parent substance according to APC $4.1(49.7 \%, n=397 / 799)$, a mixture of several parent substances $(40.8 \%, n=326)$, a composition $(6.5 \%, n=52)$, and other $(0.5 \%, n=4)$. Of the 397 AMPs with a single parental substance as starting material, the origin of the substance was mineral $(25.7 \%, n=$ $102 / 397)$, botanical $(42.6 \%, n=169)$, zoological $(23.7 \%$, $n=94)$, or it was a starting material having undergone special treatment $(8.1 \%, n=32)$.
Table 3. Route of administration of anthroposophic medicinal products (AMPs) marketed in Germany

\begin{tabular}{lrc}
\hline Route of administration & \multicolumn{2}{c}{ AMPs in Vademecum } \\
\cline { 2 - 3 } & $n$ & $\%$ \\
\hline Parenteral (injections) & 352 & 44.1 \\
Oral & 326 & 40.8 \\
Cutaneous & 81 & 10.1 \\
Rectal & 15 & 1.9 \\
Ophthalmic & 14 & 1.8 \\
Nasal & 4 & 0.5 \\
Oromucosal & 4 & 0.5 \\
Vaginal & 2 & 0.3 \\
Auricular & 1 & 0.1 \\
\hline Total & 799 & 100.0 \\
\hline
\end{tabular}

The 799 different "level 3" AMPs (AMPs of different concentrations, potencies grouped together: level 3 in Table 1) corresponded to $\mathrm{n}=1,683$ different "level 2" AMPs (each concentration or potency counted separately: level 2 in Table 1). For each of these 1,683 AMPs, the substance with the highest concentration was in concentrated form or a mother tincture in $14.0 \%(n=236 / 1,683)$ of AMPs, a $\mathrm{D} 1-\mathrm{D} 3$ potency in $19.3 \%(n=324)$ and in a $\geq \mathrm{D} 4$ potency in $66.7 \%(n=1,123)$ (further details in Table 2).

The most frequent routes of administration of the AMPs were parenteral (i.e., injection, $44.1 \%, n=352 / 799)$, oral $(40.8 \%, n=326)$, and cutaneous $(10.1 \%, n=81)$ (Table 3$)$.

\section{Indications}

Of the 625 AMP groups in the Vademecum, $0.2 \%$ ( $n=$ $1 / 624)$ had no indication, $42.6 \%(n=266)$ had 1 indication, $19.2 \%(n=120)$ had 2 indications, $13.6 \%(n=85)$ had 3 indications, $7.0 \%(n=44)$ had 4 indications, and $17.4 \%(n=109)$ had $\geq 5$ indications, with a total of 1,773 indications (median 2 indications per AMP; IQR 1-3, mean 2.8, SD 4.0, range 0-85 indications); AMPs with $\geq 10$ indications are listed in Table 4 .

The indications were based on an assessment by the Vademecum editorial board plus new report questionnaires. A total of $5.2 \%(n=92 / 1,773)$ of indications had no new report questionnaire, 64.2\% $(n=1,139)$ had 1 questionnaire, $18.4 \%(n=326)$ had 2 questionnaires, and $12.2 \%(n=216)$ had $\geq 3$ questionnaires, with a mean of 1.43 questionnaires per indication (SD 0.92, median 1, IQR 1-2, range 0-7 questionnaires).

In addition to the new report questionnaires, $7.8 \%$ $(n=136 / 1,733)$ of indications had been commented on in feedback questionnaires (127 indications had 1 questionnaire, 8 indications had 2 , and 1 indication had 3 feedback questionnaires), leading to (a) confirmation of perceived effectiveness of the AMP for the indication in question 
Table 5. Indications: ICD-10 diagnosis chapters

ICD-10 chapter

J00-J99 Diseases of the respiratory system

M00-M99 Diseases of the musculoskeletal system and connective tissue

F00-F99 Mental and behavioural disorders

K00-K93 Diseases of the digestive system

R00-R99 Symptoms, signs, and abnormal clinical and laboratory findings, not elsewhere classified

N00-N99 Diseases of the genitourinary system

L00-L99 Diseases of the skin and subcutaneous tissue

I00-I99 Diseases of the circulatory system

C00-D48 Neoplasms

G00-G99 Diseases of the nervous system

A00-B99 Certain infectious and parasitic diseases

S00-T98 Injury, poisoning, and certain other consequences of external causes

H60-H95 Diseases of the ear and mastoid process

O00-O99 Pregnancy, childbirth, and the puerperium

E00-E90 Endocrine, nutritional, and metabolic diseases

H00-H59 Diseases of the eye and adnexa

D50-D89 Diseases of the blood and blood-forming organs and certain disorders involving the immune mechanism

P00-P96 Certain conditions originating in the perinatal period

Q00-Q99 Congenital malformations, deformations, and chromosomal abnormalities

Z00-Z99 Factors influencing health status and contact with health services

V01-Y98 External causes of morbidity and mortality

U00-U85 Codes for special purposes

Total ICD-10 diagnoses
Number Percent

\begin{tabular}{rr}
254 & 11.4 \\
232 & 10.4 \\
219 & 9.9 \\
190 & 8.5 \\
181 & 8.1 \\
160 & 7.2 \\
152 & 6.8 \\
141 & 6.3 \\
128 & 5.8 \\
114 & 5.1 \\
96 & 4.3 \\
91 & 4.1 \\
57 & 2.6 \\
53 & 2.4 \\
53 & 2.4 \\
44 & 2.0 \\
23 & 1.0 \\
14 & 0.6 \\
14 & 0.6 \\
7 & 0.3 \\
0 & 0.0 \\
0 & 0.0 \\
\hline 2,223 & 100.0
\end{tabular}

( $n=131$ indications), (b) addition of critical comments such as lack of effectiveness in some cases $(n=3$ indications), or both ( $n=2$ indications).

The level of evidence for the 1,773 indications was classified by the Vademecum editorial board as "well-established, standard AMP therapy" (10.9\%, $n=193 / 1,773$ indications), "normal indications" $(80.4 \%, n=1,426)$, and "indications requiring further experience and review" $(8.7 \%, n=154)$.

Coding the 1,773 indications according to ICD-10, $80.4 \%$ of indications $(n=1,425 / 1,773)$ corresponded to one ICD-10 code, $13.6 \%(n=241)$ of indications had 2 codes, $4.1 \%(n=72)$ had 3 codes, $1.6 \%(n=28)$ had $4-6$ codes, and $0.4 \%(n=7)$ were uncodable, resulting in a total of 2,223 ICD-10 three-digit codes, thereof 544 different codes:

- The most frequent ICD-10 diagnosis chapters were J00-J99 respiratory disorders (11.4\%, $n=254 / 2,223$ diagnoses), M00-M99 musculoskeletal disorders $(10.4 \%, n=232)$, and F00-F99 mental and behavioural disorders (9.9\%, $n=219)$ (Table 5)

- The most frequent ICD-10 diagnosis blocks were F40F48 neurotic, stress-related and somatoform disorders (4.5\%, $n=101 / 2,223)$, J30-J39 other diseases of upper respiratory tract $(3.7 \%, n=83)$, N80-N98 non-inflammatory disorders of female genital tract $(3.7 \%, n=83)$, C00-C75 malignant neoplasms $(3.5 \%, n=77)$, and L20-L30 dermatitis and eczema $(3.5 \%, n=77)$
Table 6. Indications: ICD-10 three-digit codes

\begin{tabular}{lrc}
\hline ICD-10 code & Number & Percent \\
\hline J45 Asthma & 33 & 1.5 \\
L20 Atopic dermatitis & 33 & 1.5 \\
F32 Depressive episode & 31 & 1.4 \\
L30 Other dermatitis & 29 & 1.3 \\
F41 Other anxiety disorders & 28 & 1.3 \\
J32 Chronic sinusitis & 28 & 1.3 \\
G47 Sleep disorders & 26 & 1.2 \\
N94 Pain and other conditions associated with & & \\
$\quad$ female genital organs and menstrual cycle & 25 & 1.1 \\
I10 Essential (primary) hypertension & 24 & 1.1 \\
R53 Malaise and fatigue & 23 & 1.0 \\
M54 Dorsalgia & 23 & 1.0 \\
R10 Abdominal and pelvic pain & 20 & 0.9 \\
T88 Other complications of surgical and & & \\
$\quad$ medical care, not elsewhere classified & 20 & 0.9 \\
C50 Malignant neoplasm of breast & 20 & 0.9 \\
F45 Somatoform disorders & 20 & 0.9 \\
J18 Pneumonia, organism unspecified & 20 & 0.9 \\
All other ICD-10 diagnoses & 1,820 & 81.9 \\
\hline Total ICD-10 diagnoses & 2,223 & 100.0 \\
\hline
\end{tabular}

- The most frequent ICD-10 three-digit codes were J45 asthma (1.5\%, $n=33 / 2,230$ diagnoses), L20 atopic dermatitis $(1.5 \%, n=33)$, and F32 depressive episode $(1.4 \%, n=31)$ (Table 6) 
Table 7. Anthroposophic medicinal products (AMPs) in Vademecum versus AMPs in Germany

\begin{tabular}{|c|c|c|c|}
\hline AMPs & In Vademecum & $\begin{array}{l}\text { Marketed in } \\
\text { Germany 2015-2016 }\end{array}$ & $\begin{array}{l}\text { In Vademecum/ } \\
\text { in Germany, \% }\end{array}$ \\
\hline All types & 799 & 1,519 & 52.6 \\
\hline \multicolumn{4}{|l|}{ Marketed } \\
\hline With indication & 505 & 857 & 58.9 \\
\hline Without indication & 294 & 661 & 44.5 \\
\hline \multicolumn{4}{|l|}{ Route of administration ${ }^{1}$} \\
\hline Parenteral (injections) & 352 & 744 & 47.3 \\
\hline Oral & 326 & 532 & 61.3 \\
\hline Cutaneous & 81 & 160 & 50.6 \\
\hline \multicolumn{4}{|l|}{ Origin of starting material ${ }^{1,2}$} \\
\hline Mineral & 102 & 144 & 70.8 \\
\hline Botanical & 169 & 352 & 48.0 \\
\hline Zoological & 94 & 263 & 35.7 \\
\hline
\end{tabular}

${ }^{1}$ Three most common categories. ${ }^{2}$ Analysis restricted to AMPs with one starting material.

\section{Onset of Action and Therapy Duration}

Onset of action was indicated for $67.3 \%(n=$ $1,194 / 1,773)$ of indications and categorized as: $<1 \mathrm{~h}$ or "immediately" in $12.6 \%$ ( $n=151 / 1,194$ of indications), $1-23 \mathrm{~h}$ in $10.0 \%(n=119), 1-6$ days in $25.9 \%(n=309)$, $7-27$ days in $24.5 \%(n=292), \geq 28$ days in $15.1 \%(n=180)$, "rapid" (German rasch) or similar in 7.7\% $(n=92)$, "slow" in $1.0 \%(n=12)$, and not categorizable in 3.3\% $(n=39)$.

Therapy duration was indicated for $65.1 \%(n=$ $1,555 / 1,173)$ of indications and was categorized as: "single application" in $0.3 \%(n=4 / 1,155)$ of indications, $<7$ days in $9.9 \%(n=114), 1-5$ weeks in $27.3 \%(n=315), 6$ weeks to 3 months in $16.2 \%(n=187),>3$ months in $37.1 \%(n=429)$, and not categorizable in $9.2 \%(n=106)$.

\section{Recommendations for Adjunctive Therapy}

Recommendations for adjunctive therapy, e.g. with other AMPs or non-medication anthroposophic medical treatment were given for $43.9 \%(n=778 / 1,773)$ of indications.

\section{Adverse Reactions and Contraindications}

Adverse reactions were documented for $10.2 \%(n=$ $64 / 625$ ) of AMP groups, with a total of 116 free text entries of adverse reactions, corresponding to 152 MedDRA codes. Most frequent MedDRA high-level group terms for adverse reactions were administration site reactions $(30.3 \%, n=$ $46 / 152$ ), general system disorders, not elsewhere classified $(14.5 \%, n=22)$, epidermal and dermal conditions $(7.9 \%$, $n=12)$, allergic conditions $(7.2 \%, n=11)$, and body temperature conditions $(7.2 \%, n=11)$. Most frequent MedDRA system organ classes were general disorders and administration site conditions $(52.0 \%, n=79 / 152)$, psychiatric disorders $(9.9 \%, n=15)$, skin and subcutaneous tissue disorders $(9.9 \%, n=15)$, gastrointestinal disorders $(7.9 \%$, $n=12)$, and immune system disorders $(7.2 \%, n=11)$.
In addition to adverse reactions, the physicians documented contraindications to 5 AMP groups (this item was not specifically mentioned in the questionnaire).

\section{Literature References}

The Vademecum database comprised a total of 3,568 different literature references, thereof $56.2 \% \quad(n=$ $2,005 / 3,568)$ journal articles, $37.9 \%(n=1,353)$ book chapters, $4.8 \%(n=172)$ books, and $1.1 \%(n=38)$ Internet sources. Of the 2,005 journal article references, $66.2 \%$ ( $n$ $=1,327$ ) were from Der Merkurstab (Journal of Anthroposophic Medicine) (from 1946 to the present, current German name used since 1988). The references were in Ger$\operatorname{man}(89.9 \%, n=3,207 / 3,568)$ or English $(10.1 \%, n=361)$ language.

In the digital version of the Vademecum, a list of literature references is included for each AMP group. Of the 625 AMP groups, $2.6 \%(n=16 / 625)$ had no reference, $4.8 \%(n=30)$ had $1-4$ references, $14.1 \%(n=88)$ had 5-9, $30.1 \%(n=188)$ had $10-19,34.2 \%(n=214)$ had $20-49$, $9.6 \%(n=60)$ had $50-99$, and $4.6 \%(n=29)$ had $\geq 100$ references, with a median of 19 references per AMP group (IQR 10-34, range $0-1,320$, mean 30.9 references).

\section{AMPs and Indications in the Vademecum: Relative} Frequencies

The number of AMPs in the Vademecum marketed in Germany $(n=799)$ amounted to $52.6 \%(n=799 / 1,519)$ of all AMPs marketed in Germany in 2015-2016. Among 8 selected AMP subgroups (marketing status [2 subgroups], origin of starting material [3 subgroups], route of administration [3 subgroups]), this proportion ranged from $35.7 \%$ (AMPs with 1 starting material of zoological origin, $n=94 / 263$ AMPs) to $70.8 \%$ (AMPs with 1 starting material of mineral origin, $n=102 / 144$ ) (Table 7). 
The number of indications in the Vademecum, coded as ICD-10 diagnoses, was compared to all regularly used diagnoses in the ICD-10 classification system. For this analysis, the chapter U00-U85 codes for special purposes was excluded. The Vademecum had diagnoses in $95.2 \%$ $(n=20 / 21)$ of ICD-10 diagnosis chapters and $75.9 \%(n=$ 161/219) of ICD-10 diagnosis blocks, and the Vademecum ICD-10 three-digit codes amounted to $26.6 \%$ ( $n=$ $544 / 2,042$ ) of all three-digit codes (Table 7).

\section{Discussion}

\section{Overall Results}

In this first comprehensive quantitative description of the Vademecum, the AMP groups listed amounted to 53\% of all AMPs on the German market in 2015-2016. The indications for the AMPs amounted to $27 \%$ of all three-digit ICD-10 codes. Indications were based on new report questionnaires submitted by 274 physicians from 19 different countries plus assessment by the editorial team; $31 \%$ of indications were supported by 2 or more new reports.

\section{Strengths and Limitations}

Compared to much other experiential literature on WMPs, the Vademecum has a number of strengths, including a systematic, detailed and transparent documentation of clinical experiences, the broad international participation of experienced physicians, critical peer review of all reports, and independence of industry. Moreover, in addition to therapy recommendations, the Vademecum also provides readers with a comprehensive literature list for each AMP group. With regard to external validity, because of the high number of participating physicians from a range of countries, the information in the Vademecum can be assumed to be representative for the experiences of AMP prescribers.

On the other hand, compared to clinical studies, all experiential literature including the Vademecum has a fundamental design limitation in the retrospective overall assessment of the AMP therapy option, instead of prospective documentation of consecutive patients with the possibility of control groups. In spite of the detailed documentation structure of the Vademecum, the retrospective overall assessments can be biased in several ways (e.g., imprecise or selective memory, biased overall assessments) [19]. However, due to prohibitive costs, it is not feasible to conduct clinical studies for more than a fraction of all AMPs and indications. Accordingly, for a large proportion of AMPs, clinical documentation will have to rely on other types of evidence such as experiential literature including the Vademecum.

\section{Interpretation and Comparison to Other Studies}

Nearly all Vademecum indications (99.6\%) could be coded as one or several diagnoses of the ICD-10 system, and these indications amounted to $29 \%$ of all ICD- 10 three-digit codes. This reflects the strong conceptual and practical integration of AM with conventional medicine, with AMP therapy used in most medical specialties. AM involves various typologies [Baars et al., submitted 2019] but these complement rather than replace conventional medical nosology. In contrast, only one fourth of AMP groups in the Vademecum had a description of the therapeutic action according to $\mathrm{AM}$; in this respect there seems to be room for improvement. Also, less than one third of indications were supported by at least 2 new reports; an increased number of new reports per indication would give more support of plausibility for the information.

The most frequent route of administration of AMPs (44\%) was parenteral, reflecting the high importance of injections in AMP therapy [20].

For almost one third of indications, the onset of action of the AMP was described as "rapid" or within $24 \mathrm{~h}$. Such a rapid onset of action (and time period after which ineffectiveness can be assumed if no effect is registered) can be used by clinicians to monitor therapy and could be investigated further in clinical studies [21].

At the other end of the time horizon, for more than one third of indications the therapy duration exceeded 3 months, which is often needed in AMP therapy for chronic diseases [23].

Adverse reactions were reported for $10 \%$ of AMP groups. In comparison, in the EvaMed pharmacovigilance study of more than 300,000 AMP prescriptions to more than 40,000 patients, medically confirmed adverse reactions occurred to $5 \%$ of AMPs [10]. The higher frequency of adverse reactions in the Vademecum compared to EvaMed could be related to a longer observation time (lifetime experience of Vademecum physicians vs. followup of mean 27 months in EvaMed).

\section{Implications and Future Developments}

The Vademecum has been developed as a guidance tool for physicians prescribing AMPs, and the results of this analysis can serve as feedback to the Vademecum project.

In addition, the Vademecum can be used as a source of experiential evidence for scientific and regulatory assessment of AMPs. ESCAMP is developing a scientific basis for an appropriate regulatory framework for AMPs, and the results of this analysis can yield background information for scenario analyses with alternative regulatory models: "If a certain set of criteria is applied for experiential evidence, what proportion of AMPs and indications would fulfil these criteria in the current Vademecum?" and "What would need to be added, in 
order to increase this proportion by a certain degree?" Furthermore, for specific AMPs or AMP groups, the effort and benefit of added experiential evidence in the $\mathrm{Va}$ demecum project can be weighed against other approaches to increase the evidence base, such as high-quality case reports $[22,24]$, registry and real-world data studies, and clinical trials.

Notably, if the Vademecum is to be used for regulatory purposes, certain technical limitations of the present version should be overcome. This issue has been discussed at length elsewhere [19], and corresponding work to improve future editions has started.

This quantitative description of the Vademecum documentation system for therapy experiences of AM physicians with AMPs may also be useful for similar projects for other WMPs. In Germany, such a project has been launched (Hufeland-Vademecum, http://www.hufelandgesellschaft.de/vademecum.html). The Vademecum approach may also be relevant for screening programmes for medicinal plants as potential drugs for specific diseases [25].

\section{Conclusions}

This analysis of the Vademecum of Anthroposophic Medicines shows that it is possible to document, critically assess, and aggregate experiential evidence among a large group of therapy providers for a large number of WMPs in a systematic and transparent way. The Vademecum has a potential for scientific and regulatory assessment of AMPs, and the Vademecum approach may be relevant for WMPs from other whole medical systems and for screening programmes for medicinal plants as potential drugs for specific diseases.

\section{Acknowledgement}

We thank Dr. Markus Karutz, co-manager of the Vademecum, for providing information on details of the project.

\section{Statement of Ethics}

This analysis does not include any data on treatment of individual patients, hence no ethical approval was necessary. Data were derived from sources publicly available for a small charge (Vademecum, 4th edition [15]). The publication was prepared according to the STROBE guidelines for cross-sectional observational studies [26].

\section{Disclosure Statement}

H.J.H. is member of the GAÄD and is scientific director and president of ESCAMP. G.S. and A.G. are members of ESCAMP. J.M. is secretary of GAÄD. G.S. is member of the Extended Board of the GAÄD, member of the Commission C of the Federal Institute of Drugs and Medical Devices (BfArM), and deputy head of the Medical Section at the Goetheanum.

\section{Funding Sources}

The Vademecum is published and distributed by the GAÄD, a non-profit organization. All documentation and editorial work by the involved physicians including board members is done without remuneration. A study analysis commissioned by the Vademecum for the special section on mistletoe products was funded by the Mahle-Stiftung (\#140108) and the Dr.-Hauschka-Stiftung (15-102014). Technical support and printing costs are covered by sales revenue. AMP manufacturers provided information on the regulatory status of AMPs marketed in Germany as well as scientific literature from their archives, otherwise they had no intellectual input and no involvement with the project.

This analysis was commissioned by ESCAMP, a non-profit organization which has received unrestricted grants from the Christophorus-Stiftung (306 CST, 333 CST), Mahle-Stiftung (\#170128, \#180133), Software-AG-Stiftung (SE-P 11437), Wala Heilmittel $\mathrm{GmbH}$, and Weleda AG. The sponsors had no influence on the planning or conduct of the Vademecum project, the analysis or interpretation of data, or on the writing of this paper.

\section{Author Contributions}

G.S. is co-founder and co-manager of the Vademecum project. J.M. is responsible for the Vademecum database, extracted data for analysis, had access to all data, and is guarantor. H.J.H. and A.G. wrote the analysis plan. A.G. and J.M. analysed data. H.J.H. was principal author. All authors participated in critical revision of the manuscript and approved the final paper.

\section{References}

1 Kessler C, Michalsen A. The role of whole medical systems in global medicine. Forsch Komplement Med. 2012;19(2):65-6.

2 Baars EW, Hamre HJ. Whole medical systems versus the system of conventional biomedicine: a critical, narrative review of similarities, differences, and factors that promote the integration process. Evid Based Complement Alternat Med. 2017;2017: 4904930.

3 Pathway for licensing natural health products used as traditional medicines. Ottawa: Health Canada; 2012. 26 pp.
4 Ordinance on complementary and herbal medicinal products, KPAV/OAMédcophy [Verordnung des Schweizerischen Heilmittelinstituts über die vereinfachte Zulassung von Komplementär- und Phytoarzneimitteln (Komplementär- und Phytoarzneimittelverordnung, KPAV) vom 22. Juni 2006 (Stand am 1. Juni 2011)]. Bern: The Institute Council of the Swiss Agency for Therapeutic Products; 2011 Jan 6.

5 Directive 2004/24/EC of the European Parliament and of the Council of 31 March 2004, amending, as regards traditional herbal me- dicinal products, Directive 2001/83/EC on the Community code relating to medicinal products for human use. Official J Eur Union. 2004;L136:85-90.

6 Kienle GS, Albonico HU, Baars E, Hamre HJ, Zimmermann P, Kiene H. Anthroposophic medicine: an integrative medical system originating in europe. Glob Adv Health Med. 2013 Nov;2(6):20-31.

7 Facts and figures on anthroposophic medicine worldwide. Brussels: IVAA - International Federation of Anthroposophic Medical Associations; 2012 Jul. 
8 Jones G, Pedersen P, Schwarz R, Mennet-von Eiff M, editors. Anthroposophic pharmaceutical codex APC. Edition 4.1. Dornach: International Association of Anthroposophic Pharmacists; 2018.

9 Kienle GS, Glockmann A, Grugel R, Hamre HJ, Kiene H. Klinische Forschung zur anthroposophischen Medizin - Update eines «Health Technology Assessment»-Berichts und Status quo [Clinical research on anthroposophic medicine: update of a health technology assessment report and status quo]. Forsch Komplementmed. 2011;18(5):269-82.

10 Hamre HJ, Glockmann A, Heckenbach K, Matthes $\mathrm{H}$. Use and safety of anthroposophic medicinal products: an analysis of 44,662 patients from the EvaMed Pharmacovigilance Network. Drugs Real World Outcomes. 2017 Dec;4(4):199-213.

11 Schramm H. Heilmittel der anthroposophischen Medizin. Grundlagen, Arzneimittelporträts, Awendung. München: Urban \& Fischer Verlag; 2009. 614 pp.

12 Girke M. Innere Medizin - Grundlagen und therapeutische Konzepte der Anthroposophischen Medizin. 2. Berlin: Salumed-Verlag; 2012. 1168 pp.

13 Glöckler M, editor. Anthroposophische Arzneitherapie für Ärzte und Apotheker [Anthroposophic medication therapy for physicians and pharmacists]. 1. Aufl. mit 5. Aktualisierungslieferung. Stuttgart: Deutscher Apotheker Verlag; 2014.
14 Roemer F. Therapiekonzepte der Anthroposophischen Medizin. Stufenpläne mit Differenzialdiagnostik. Stuttgart: Karl F. Haug Verlag; 2014. 442 pp.

15 Arendt A, Debus M, Karutz M, Kienle GS, Kuck A, Kummer K-R, et al. Vademecum anthroposophische Arzneimittel, 4. deutsche, überarbeitete und erweiterte Aufl. Merkurstab. 2017;70(5, Suppl).

16 Arendt A, Debus M, Karutz M, Kienle GS, Kuck A, Kummer KR, et al. Vademecum of anthroposophic medicines. 3rd English ed. Merkurstab/J Anthroposoph Med. 2017;70(2 Suppl): 1436

17 Heusser P, Kienle GS. Anthroposophic medicine, integrative oncology, and mistletoe therapy of cancer. In: Abrams DI, Weil A, editors. Integrative oncology. 2nd ed. New York: Oxford University Press; 2014. p. 560-78.

18 Arzneimittelgesetz in der Fassung der Bekanntmachung vom 12. Dezember 2005 (BGBl. I S. 3394), das zuletzt durch Artikel 2a des Gesetzes vom 27. März 2014 (BGBl. I S. 261) geändert worden ist. Bonn: Bundesministerium der Justiz und für Verbraucherschutz; 2014.

19 Hamre HJ. Scientific relevance of the vademecum of anthroposophic medicines. Merkurstab. 2018;71(2):120-4
20 Baars EW. The benefit/risk balance of subcutaneous injections as used in homeopathy and anthroposophic medicine: a narrative literature review. Eur J Integr Med. 2017;15:1-9.

21 Hamre HJ, Mittag I, Glockmann A, Kiene H, Tröger W. Pulpa dentis D30 for acute reversible pulpitis: A prospective cohort study in routine dental practice. Altern Ther Health Med. 2011 Jan-Feb;17(1):16-21.

22 Riley DS, Barber MS, Kienle GS, Aronson J, von Schoen-Angerer T, Tugwell $\mathrm{P}$, et al. CARE 2013 explanations and elaborations: reporting guidelines for case reports. J Clin Epidemiol. 2017;89:218-35.

23 Hamre HJ, Witt CM, Glockmann A, Ziegler R, Kienle GS, Willich SN, et al. Outcome of anthroposophic medication therapy in chronic disease: a 12-month prospective cohort study. Drug Des Devel Ther. 2009 Feb;2: 25-37.

24 Kiene H, Hamre HJ, Kienle GS. In support of clinical case reports: a system of causality assessment. Glob Adv Health Med. 2013 Mar; 2(2):64-75.

25 Elsas SM. A model on how to obtain data from botanical practitioners. Epilepsy Behav. 2015; 52(Pt B):333-7.

26 von Elm E, Altman DG, Egger M, Pocock SJ, Gøtzsche PC, Vandenbroucke JP; STROBE Initiative. Strengthening the Reporting of Observational Studies in Epidemiology (STROBE) statement: guidelines for reporting observational studies. BMJ. 2007 Oct; 335(7624):806-8. 